\title{
Front Matter: Volume 7961
}

, "Front Matter: Volume 7961," Proc. SPIE 7961, Medical Imaging 2011:

Physics of Medical Imaging, 796101 (22 April 2011); doi: 10.1117/12.895342

SPIE Event: SPIE Medical Imaging, 2011, Lake Buena Vista (Orlando), Florida, United States 


\title{
PROGRESS IN BIOMEDICAL OPTICS AND IMAGING
}

Vol. 12 , No. 30

\section{Medical Imaging 2011}

\section{Physics of Medical Imaging}

\author{
Norbert J. Pelc \\ Ehsan Samei \\ Robert M. Nishikawa
}

Editors

13-17 February 2011

Lake Buena Vista, Florida, United States

Sponsored by

SPIE

Cosponsored by

Dynasil Corporation/RMD Research (United States) - AAPM-American Association of Physicists in Medicine (United States) - DQE Instruments, Inc. (Canada) • Ocean Thin Films, Inc. (United States) - CREOL-The College of Optics and Photonics, Univ. of Central Florida (United States) VIDA Diagnostics, Inc. (United States)

Cooperating Organizations

APS—American Physiological Society (United States) • CARS—Computer Assisted Radiology and Surgery (Germany) • The Society for Imaging Science and Technology • Medical Image Perception Society (United States) • Radiological Society of North America (United States) Society for Imaging Informatics in Medicine (United States) • SMI-The Society for Molecular Imaging • The DICOM Standards Committee (United States)

Published by

SPIE

Volume 7961

Part One of Three Parts

Proceedings of SPIE, 1605-7422, v. 7961

SPIE is an international society advancing an interdisciplinary approach to the science and application of light. 
The papers included in this volume were part of the technical conference cited on the cover and title page. Papers were selected and subject to review by the editors and conference program committee. Some conference presentations may not be available for publication. The papers published in these proceedings reflect the work and thoughts of the authors and are published herein as submitted. The publisher is not responsible for the validity of the information or for any outcomes resulting from reliance thereon.

Please use the following format to cite material from this book:

Author(s), "Title of Paper," in Medical Imaging 2011: Physics of Medical Imaging, edited by Norbert J. Pelc, Ehsan Samei, Robert M. Nishikawa, Proceedings of SPIE Vol. 7961 (SPIE, Bellingham, WA, 2011 ) Article CID Number.

ISSN 1605-7422

ISBN 9780819485038

Published by

SPIE

P.O. Box 10, Bellingham, Washington 98227-0010 USA

Telephone +1 3606763290 (Pacific Time) · Fax +1 3606471445

SPIE.org

Copyright (C) 2011, Society of Photo-Optical Instrumentation Engineers.

Copying of material in this book for internal or personal use, or for the internal or personal use of specific clients, beyond the fair use provisions granted by the U.S. Copyright Law is authorized by SPIE subject to payment of copying fees. The Transactional Reporting Service base fee for this volume is $\$ 18.00$ per article (or portion thereof), which should be paid directly to the Copyright Clearance Center (CCC), 222 Rosewood Drive, Danvers, MA 01923. Payment may also be made electronically through CCC Online at copyright.com. Other copying for republication, resale, advertising or promotion, or any form of systematic or multiple reproduction of any material in this book is prohibited except with permission in writing from the publisher. The CCC fee code is 1605 $7422 / 11 / \$ 18.00$.

Printed in the United States of America.

Publication of record for individual papers is online in the SPIE Digital Library.

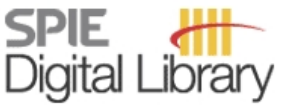

SPIEDigitallibrary.org

Paper Numbering: Proceedings of SPIE follow an e-First publication model, with papers published first online and then in print and on CD-ROM. Papers are published as they are submitted and meet publication criteria. A unique, consistent, permanent citation identifier (CID) number is assigned to each article at the time of the first publication. Utilization of CIDs allows articles to be fully citable as soon they are published online, and connects the same identifier to all online, print, and electronic versions of the publication. SPIE uses a six-digit CID article numbering system in which:

- The first four digits correspond to the SPIE volume number.

- The last two digits indicate publication order within the volume using a Base 36 numbering system employing both numerals and letters. These two-number sets start with $00,01,02,03,04$, $05,06,07,08,09,0 A, 0 B \ldots$. 0Z, followed by 10-1Z, 20-2Z, etc.

The CID number appears on each page of the manuscript. The complete citation is used on the first page, and an abbreviated version on subsequent pages. Numbers in the index correspond to the last two digits of the six-digit CID number. 


\section{Contents}

xxv Conference Committee

\section{Part One}

SESSION 1 KEYNOTE AND IMAGING AND HEALTH ECONOMICS

796103 Lateral organic photodetectors for imaging applications [7961-02]

U. Shafique, K. S. Karim, Univ. of Waterloo (Canada)

796104 Design and optimization of a dedicated cone-beam CT system for musculoskeletal extremities imaging [7961-03]

W. Zbijewski, P. De Jean, P. Prakash, Y. Ding, J. W. Stayman, The Johns Hopkins Univ. (United States); N. Packard, R. Senn, D. Yang, J. Yorkston, Carestream Health, Inc. (United States); A. Machado, J. A. Carrino, J. H. Siewerdsen, The Johns Hopkins Univ. (United States)

\section{SESSION $2 \quad$ X-RAY IMAGING}

796106 A laser-driven undulator x-ray source: simulation of image formation and dose deposition in mammography [7961-05]

B. Müller, Ludwig-Maximilians-Univ. München (Germany) and Helmholtz Zentrum München GmbH (Germany); H. Schlattl, Helmholtz Zentrum München GmbH (Germany); F. Grüner, Ludwig-Maximilians-Univ. München (Germany); C. Hoeschen, Helmholtz Zentrum München GmbH (Germany)

796107 The case for single-exposure angiography using energy-resolving photon-counting detectors: a theoretical comparison of signal and noise with conventional subtraction angiography [7961-06]

J. Tanguay, Robarts Research Institute (Canada) and The Univ. of Western Ontario (Canada); H. K. Kim, The Univ. of Western Ontario (Canada) and Pusan National Univ. (Korea, Republic of); I. A. Cunningham, Robarts Research Institute (Canada), The Univ. of Western Ontario (Canada), and Lawson Health Research Institute (Canada)

796108 Electron field emission Particle-In-Cell (PIC) coupled with MCNPX simulation of a CNT-based flat-panel x-ray source [7961-07]

E. J. Grant, C. M. Posada, C. H. Castaño, H. K. Lee, Missouri Univ. of Science and Technology (United States)

796109 The effects of compensator design on scatter distribution and magnitude: a Monte Carlo study [7961-08]

G. J. Bootsma, Univ. of Toronto (Canada) and Princess Margaret Hospital (Canada);

F. Verhaegen, Maastricht Univ. Medical Ctr. (Netherlands) and McGill Univ. (Canada);

D. A. Jaffray, Univ. of Toronto (Canada) and Princess Margaret Hospital (Canada) 
7961 OA Correlated-polarity noise reduction: feasibility of a new statistical approach to reduce image noise [7961-133]

J. T. Dobbins III, Duke Univ. Medical Ctr. (United States) and Duke Univ. (United States);

J. R. Wells, Duke Univ. Medical Ctr. (United States)

$7961 \mathrm{OB}$ Optimization of the grid frequencies and angles in digital radiography imaging [7961-10] D. S. Kim, Hankuk Univ. of Foreign Studies (Korea, Republic of); S. Lee, DRTech Co. (Korea, Republic of)

\section{SESSION 3 METROLOGY}

7961 OC A novel method to measure the zero-frequency DQE of a non-linear imaging system [7961-11]

M. C. McDonald, The Univ. of Western Ontario (Canada); H. K. Kim, Pusan National Univ. (Korea, Republic of); J. H. Henry, London Health Sciences Ctr (Canada); I. A. Cunningham, The Univ. of Western Ontario (Canada) and London Health Sciences Ctr (Canada)

7961 OD Use of sphere phantoms to measure the 3D MTF of FDK reconstructions [7961-12] J. Baek, N. J. Pelc, Stanford Univ. (United States)

7961 OE 3D noise power spectrum applied on clinical MDCT scanners: effects of reconstruction algorithms and reconstruction filters [7961-13]

F. A. Miéville, Univ. Hospital Ctr. (Switzerland) and Univ. of Lausanne (Switzerland); G. Bolard, Clinic of Genolier (Switzerland); M. Benkreira, Univ. Hospital Ctr. (Switzerland) and Univ. of Lausanne (Switzerland); P. Ayestaran, General Electric Medical Systems Europe (France); F. Gudinchet, F. Bochud, F. R. Verdun, Univ. Hospital Ctr. (Switzerland) and Univ. of Lausanne (Switzerland)

7961 OF NPS comparison of anatomical noise characteristics in mammography, tomosynthesis, and breast CT images using power law metrics [7961-14]

L. Chen, J. M. Boone, A. Nosratieh, Univ. of California. Davis (United States); C. K. Abbey, Univ. of California, Santa Barbara (United States)

$79610 G \quad$ Imaging properties of the magnification factor in digital mammography by the generalized MTF (GMTF) [7961-15]

H.-S. Park, H.-J. Kim, H.-M. Cho, C.-L. Lee, D.-H. Kim, S.-W. Lee, Y.-N. Choi, Yonsei Univ. (Korea, Republic of)

\section{SESSION 4 ITERATIVE AND STATISTICAL RECONSTRUCTION}

$7961 \mathrm{OH} \quad$ Predictive models for observer performance in CT: applications in protocol optimization [7961-16]

S. Richard, X. Li, Duke Univ. (United States); G. Yadava, GE Healthcare (United States);

E. Samei, Duke Univ. (United States)

79610 Ol High-order noise analysis for low dose iterative image reconstruction methods: ASIR, IRIS, and MBAl [7961-17]

S. Do, S. Singh, M. K. Kalra, Massachusetts General Hospital (United States) and Harvard Medical School (United States); W. C. Karl, Boston Univ. (United States); T. J. Brady, H. Pien, Massachusetts General Hospital (United States) and Harvard Medical School (United States) 
7961 0J Adaptive iterative reconstruction [7961-18]

H. Bruder, R. Raupach, J. Sunnegardh, M. Sedlmair, K. Stierstorfer, T. Flohr, Siemens

Healthcare (Germany)

7961 OK Fast iterative image reconstruction using sparse matrix factorization with GPU acceleration [7961-19]

J. Zhou, J. Qi, Univ. of California, Davis (United States)

7961 OL Precision of iodine quantification in hepatic CT: effects of reconstruction (FBP and MBIR) and imaging parameters [7961-20]

B. Chen, E. Samei, J. Colsher, H. Barnhart, D. Marin, R. Nelson, Duke Univ. (United States)

7961 OM An iterative dual energy CT reconstruction method for a K-edge contrast material [7961-21] M. Depypere, J. Nuyts, N. van Gastel, G. Carmeliet, F. Maes, P. Suetens, Katholieke Univ. Leuven (Belgium)

\section{SESSION 5 DETECTORS I}

7961 ON Novel synthesis of large area ZnTe:O films for high-resolution imaging applications [7961-22] V. V. Nagarkar, B. Singh, V. B. Gaysinskiy, S. R. Miller, V. Gelfandbein, H. Bhandari, M. Squillante, Radiation Monitoring Devices, Inc. (United States)

796100 12-inch-wafer-scale CMOS active-pixel sensor for digital mammography [7961-23] S. K. Heo, J. Kosonen, S. H. Hwang, T. W. Kim, Vatech Humanray Co., Ltd. (Korea, Republic of); S. Yun, H. K. Kim, Pusan National Univ. (Korea, Republic of)

7961 OP Noise performance limits of advanced $x$-ray imagers employing poly-Si-based active pixel architectures [7961-24]

M. Koniczek, Y. El-Mohri, L. E. Antonuk, A. Liang, Q. Zhao, H. Jiang, Univ. of Michigan (United States)

$79610 Q$ Characterization and comparison of lateral amorphous semiconductors with embedded Frisch grid detectors on $0.18 \mu \mathrm{m}$ CMOS processed substrate for medical imaging applications [7961-25]

C. Hristovski, A. Goldan, S. H. Majid, K. Wang, U. Shafique, K. Karim, Univ. of Waterloo (Canada)

7961 OR Low-noise thin-film transistor array for digital x-ray imaging detectors [7961-26]

D. Lee, Directxray Digital Imaging Technology LLC (United States)

\section{SESSION 6 DETECTORS II}

7961 OS Performance characterization of a silicon strip detector for spectral computed tomography utilizing a laser testing system [7961-27]

C. Xu, M. Danielsson, S. Karlsson, Royal Institute of Technology (Sweden); C. Svensson, Linköping Univ. (Sweden); H. Bornefalk, Royal Institute of Technology (Sweden)

7961 OT Quantum-counting CT in the regime of count-rate paralysis: introduction of the pile-up trigger method [7961-28]

S. Kappler, S. Hölzer, E. Kraft, K. Stierstorfer, T. Flohr, Siemens Healthcare (Germany) 
7961 OU 6-Li enriched Cs $2 L_{\text {LiYCl}}$ :Ce based thermal neutron detector coupled with CMOS solid-state photomultipliers for a portable detector unit [7961-29]

C. Whitney, C. Stapels, E. Johnson, E. Chapman, G. Alberghini, J. Glodo, K. Shah, J. Christian, Radiation Monitoring Devices, Inc. (United States)

7961 OV Integration of an amorphous silicon passive pixel sensor array with a lateral amorphous selenium detector for large area indirect conversion x-ray imaging applications [7961-30]

K. Wang, Univ. of Waterloo (Canada) and Thunder Bay Regional Research Institute (Canada); M. Y. Yazdandoost, R. Keshavarzi, K.-W. Shin, C. Hristovski, S. Abbaszadeh, F. Chen, S. H. Majid, K. S. Karim, Univ. of Waterloo (Canada)

7961 OW Simulation of one-dimensionally polarized $\mathbf{x}$-ray semiconductor detectors [7961-31] K. J. Engel, C. Herrmann, Philips Research Labs. (Germany)

7961 OX Electrical interface characteristics (I-V), optical time of flight measurements, and the $x$-ray (20 kev) signal response of amorphous-selenium/crystalline-silicon heterojunction structures [7961-32]

D. M. Hunter, C. A. Ho, Sunnybrook Health Sciences Ctr. (Canada); G. Belev, Univ. of Saskatchewan (Canada); G. De Crescenzo, Thunder Bay Regional Research Institute (Canada); S. O. Kasap, Univ. of Saskatchewan (Canada); M. J. Yaffe, Sunnybrook Health Sciences Ctr. (Canada) and Univ. of Toronto (Canada)

$79610 Z$ Comparison of 3D and 2D breast density estimation from synthetic ultrasound tomography images and digital mammograms of anthropomorphic software breast phantoms [7961-34] P. R. Bakic, Univ. of Pennsylvania (United States); C. Li, E. West, M. Sak, Karmanos Cancer Institute, Wayne State Univ. (United States); S. C. Gavenonis, Univ. of Pennsylvania (United States); N. Duric, Karmanos Cancer Institute, Wayne State Univ. (United States);

A. D. A. Maidment, Univ. of Pennsylvania (United States)

796110 The effect of characteristic x-rays on the spatial and spectral resolution of a CZT-based detector for breast CT [7961-35]

S. J. Glick, Univ. of Massachusetts Medical School (United States); C. S. Didier, Massachusetts Institute of Technology (United States)

796111 Analysis of multilayer and single layer x-ray detectors for contrast-enhanced mammography using imaging task [7961-36]

N. Allec, S. Abbaszadeh, K. S. Karim, Univ. of Waterloo (Canada)

796112 Optimization of mammography with respect to anatomical noise [7961-37]

E. Fredenberg, Royal Institute of Technology (Sweden); B. Svensson, Sectra Mamea AB

(Sweden); M. Danielsson, Royal Institute of Technology (Sweden); B. Lazzari, General

Hospital of Pistoia (Italy); B. Cederström, Royal Institute of Technology (Sweden)

796113 Issues in characterizing anatomic structure in digital breast tomosynthesis [7961-38]

B. A. Lau, I. Reiser, R. M. Nishikawa, The Univ. of Chicago (United States) 
$796114 \quad$ Evaluation of photon-counting spectral breast tomosynthesis [7961-39]

N. Dahlman, E. Fredenberg, Royal Institute of Technology (Sweden); M. Åslund, M. Lundqvist, Sectra Mamea AB (Sweden); F. Diekmann, Charité Univ. Hospital (Germany); M. Danielsson, Royal Institute of Technology (Sweden)

\section{SESSION 8 TOMOSYNTHESIS I: RECONSTRUCTION}

796115 Tomosynthesis imaging with 2D scanning trajectories [7961-40]

K. Khare, B. E. H. Claus, J. W. Eberhard, GE Global Research (United States)

796116 Dynamic reconstruction and rendering of 3D tomosynthesis images [7961-41]

J. Kuo, P. A. Ringer, S. G. Fallows, Real-Time Tomography, LLC (United States); P. R. Bakic,

A. D. A. Maidment, Univ. of Pennsylvania (United States); S. Ng, Real-Time Tomography, LLC (United States)

796117 Adaptive diffusion regularization for enhancement of microcalcifications in digital breast tomosynthesis (DBT) reconstruction [7961-42]

Y. Lu, H.-P. Chan, J. A. Fessler, L. Hadjiiski, J. Wei, M. M. Goodsitt, Univ. of Michigan (United States)

796118 Comparison of model-observer and human-observer performance for breast tomosynthesis: effect of reconstruction and acquisition parameters [7961-43] M. Das, H. C. Gifford, Univ. of Massachusetts Medical School (United States)

796119 A second pass correction method for calcification artifacts in digital breast tomosynthesis [7961-44]

K. Erhard, M. Grass, T. Nielsen, Philips Research Labs. Hamburg (Germany)

\section{SESSION 9 TOMOSYNTHESIS II}

7961 1A 3D task-based performance assessment metrics for optimization of performance and dose in breast tomosynthesis [7961-45]

S. Richard, E. Samei, Duke Univ. (United States)

7961 1B Dose and diagnostic image quality in digital tomosynthesis imaging of facial bones in pediatrics [7961-46]

J. M. King, CancerCare Manitoba (Canada); S. Hickling, CancerCare Manitoba (Canada) and The Univ. of Western Ontario (Canada); I. A. Elbakri, CancerCare Manitoba (Canada) and Univ. of Manitoba (Canada); M. Reed, J. Wrogemann, The Children's Hospital of Winnipeg (Canada)

7961 1C A 3D linear system model for the optimization of dual-energy contrast-enhanced digital breast tomosynthesis [7961-47]

Y.-H. Hu, W. Zhao, Stony Brook Univ. Health Sciences Ctr. (United States)

7961 1D Effects of image lag and scatter for dual-energy contrast-enhanced digital breast tomosynthesis using a Csl flat-panel based system [7961-48]

A.-K. Carton, S. Puong, R. lordache, S. Muller, GE Healthcare France (France) 
$7961 \mathrm{lE}$ Investigation of the effect of tube motion in breast tomosynthesis: continuous or step and shoot? [7961-49]

E. Shaheen, N. Marshall, H. Bosmans, Univ. Hospitals Leuven (Belgium)

7961 IF Real-time scanning beam digital $x$-ray image guidance system for transbronchial needle biopsy [7961-50]

S. Yoon, Stanford Univ. (United States); B. P. Wilfley, Triple Ring Technologies, Inc. (United States); K. Jasperson, superDimension, Inc. (United States); G. Krishna, Palo Alto Medical

Foundation (United States); R. Fahrig, Stanford Univ. (United States)

\section{SESSION $10 \quad$ X-RAY IMAGING: PHASE CONTRAST, DIFFRACTION}

7961 IG Towards $x$-ray differential phase contrast imaging on a compact setup [7961-51]

T. Thüring, Paul Scherrer Institute (Switzerland) and Swiss Federal Institute of Technology (Switzerland); P. Modregger, Paul Scherrer Institute (Switzerland) and Univ. of Lausanne (Switzerland); B. R. Pinzer, Z. Wang, Paul Scherrer Institute (Switzerland); S. Rutishauser, Swiss Federal Institute of Technology (Switzerland) and Paul Scherrer Institute (Switzerland); C. David, Paul Scherrer Institute (Switzerland); T. Grund, J. Kenntner, Karlsruhe Institute of Technology (KIT) (Germany); M. Stampanoni, Paul Scherrer Institute (Switzerland) and Swiss Federal Institute of Technology (Switzerland)

$7961 \mathrm{lH} \quad$ Beam hardening in x-ray differential phase contrast computed tomography [7961-52] N. Bevins, J. Zambelli, K. Li, Z. Qi, G.-H. Chen, Univ. of Wisconsin-Madison (United States)

7961 1J Spectroscopic measurements concerning grating-based x-ray phase-contrast imaging [7961-54]

T. Weber, P. Bartl, F. Bayer, J. Durst, W. Haas, T. Michel, G. Pelzer, A. Ritter, G. Anton, Friedrich-Alexander-Univ. of Erlangen-Nürnberg (Germany)

7961 1K 3D diffraction tomography for visualization of contrast media [7961-55]

V. M. Pai, National Institutes of Health (United States); A. Stein, Harvard Medical School (United States); M. Kozlowski, A. George, National Institutes of Health (United States); R. Kopace, Duke Univ. (United States); E. Bennett, National Institutes of Health (United States); J. A. Auxier, Oregon State Univ. (United States); H. Wen, National Institutes of Health (United States)

\section{SESSION 11 IMAGE RECONSTRUCTION}

7961 1L Penalized-likelihood reconstruction for sparse data acquisitions with unregistered prior images and compressed sensing penalties [7961-56]

J. W. Stayman, W. Zbijewski, Y. Otake, A. Uneri, S. Schafer, J. Lee, J. L. Prince, J. H. Siewerdsen, Johns Hopkins Univ. (United States)

$79611 \mathrm{M}$ Quantification of temporal resolution and its reliability in the context of TRI-PICCS and dual source CT [7961-57]

C. Maaß, M. Kachelrieß, Friedrich-Alexander-Univ. Erlangen-Nürnberg (Germany)

7961 iN Evaluation of a novel CT image reconstruction algorithm with enhanced temporal resolution [7961-58]

H. Schöndube, T. Allmendinger, K. Stierstorfer, H. Bruder, T. Flohr, Siemens AG (Germany) 
796110 A Compton imaging algorithm for on-line monitoring in hadron therapy [7961-59]

J. E. Gillam, C. Lacasta, I. Torres-Espallardo, C. Candela Juan, G. Llosá, P. Solevi, J. Barrio, M. Rafecas, Univ. de València (Spain)

7961 1P Method for reducing windmill artifacts in multislice CT images [7961-60]

K. M. Brown, S. Žabić, Philips Healthcare (United States)

7961 1Q Helical x-ray differential phase contrast computed tomography [7961-61]

Z. Qi, P. Thériault-Lauzier, N. Bevins, J. Zambelli, K. Li, G.-H. Chen, Univ. of Wisconsin-Madison (United States)

\section{SESSION 12 CT III: MULTI-ENERGY}

7961 IR Synthetic CT: simulating arbitrary low dose single and dual energy protocols [7961-62] A. S. Wang, N. J. Pelc, Stanford Univ. (United States)

7961 is A tabletop clinical x-ray CT scanner with energy-resolving photon counting detectors [7961-63]

J. Cammin, S. Srivastava, The Johns Hopkins Univ. School of Medicine (United States);

W. C. Barber, J. S. Iwanczyk, N. E. Hartsough, DxRay Inc. (United States); E. Nygard,

J. C. Wessel, N. Malakhov, Interon AS (Norway); K. Taguchi, The Johns Hopkins Univ. School of Medicine (United States)

7961 IT Investigating possible improvements in image quality with energy-weighting photon-counting breast CT [7961-64]

S. J. Glick, Univ. of Massachusetts Medical School (United States); K. Kalluri, Univ. of Massachusetts at Lowell (United States)

$79611 \mathrm{U}$ Temporal and spectral reconstruction algorithms for $\mathbf{x}$-ray CT [7961-65]

S. M. Johnston, Duke Univ. (United States) and Duke Univ. Medical Ctr. (United States);

C. T. Badea, Duke Univ. Medical Ctr. (United States)

7961 IV Material separation in x-ray CT with energy resolved photon-counting detectors [7961-66]

$X$. Wang, The Johns Hopkins Univ. (United States); D. Meier, Gamma Medica-Ideas (Norway);

K. Taguchi, The Johns Hopkins Univ. (United States); D. J. Wagenaar, B. E. Patt, Gamma Medica-Ideas, Inc. (United States); E. C. Frey, The Johns Hopkins Univ. (United States)

\section{SESSION 13 NOVEL SYSTEMS}

7961 IW An inverse geometry CT system with stationary source arrays [7961-67]

S. S. Hsieh, Stanford Univ. (United States); J. A. Heanue, T. Funk, Triple Ring Technologies, Inc. (United States); W. S. Hinshaw, Stanford Univ. (United States) and Triple Ring Technologies,

Inc. (United States); N. J. Pelc, Stanford Univ. (United States)

$79611 \mathrm{X}$ Dual-energy micro-CT imaging for differentiation of iodine- and gold-based nanoparticles [7961-68]

C. T. Badea, S. M. Johnston, Y. Qi, Duke Univ. Medical Ctr. (United States); K. Ghaghada, Univ. of Texas Health Sciences Ctr. (United States); G. A. Johnson, Duke Univ. Medical Ctr. (United States) 
79611 1Y Design and development of MR-compatible SPECT systems for simultaneous SPECT-MR imaging of small animals [7961-69]

B. M. Tsui, The Johns Hopkins Univ. (United States); J. W. Hugg, Gamma Medica-Ideas, Inc. (United States); J. Xu, S. Chen, The Johns Hopkins Univ. (United States); D. Meier, Gamma Medica-Ideas, Inc. (United States); W. Edelstein, A. El-Sharkawy, The Johns Hopkins Univ. (United States); D. J. Wagenaar, B. E. Patt, Gamma Medica-Ideas, Inc. (United States)

$79611 Z$ Freehand SPECT in low uptake situations [7961-70]

T. Lasser, S. I. Ziegler, N. Navab, Technische Univ. München (Germany)

796120 Forward model of Cerenkov luminescence tomography with the third-order simplified spherical harmonics approximation [7961-71]

J. Zhong, J. Tian, X. Yang, C. Qin, Institute of Automation (China)

$796121 \quad$ A preclinical SPECT camera with depth-of-interaction compensation using a focused-cut scintillator [7961-72]

F. Alhassen, Univ. of California, San Francisco (United States); H. Kudrolli, B. Singh, Radiation Monitoring Devices, Inc. (United States); S. Kim, Y. Seo, R. G. Gould, Univ. of California, San Francisco (United States); V. V. Nagarkar, Radiation Monitoring Devices, Inc. (United States)

\section{SESSION 14 CT IV: CONE BEAM}

796122 Evaluation of an erbium modulator in x-ray scatter correction using primary modulation [7961-73]

H. Gao, Stanford Univ. (United States); T. Niu, L. Zhu, Georgia Institute of Technology (United States); R. Fahrig, Stanford Univ. (United States)

796123 Analysis of vertical and horizontal circular C-arm trajectories [7961-74] A. Maier, J.-H. Choi, A. Keil, Stanford Univ. (United States); C. Niebler, Friedrich-Alexander-Univ. Erlangen-Nürnberg (Germany); M. Sarmiento, Siemens AG (Germany); A. Fieselmann, Friedrich-Alexander-Univ. Erlangen-Nürnberg (Germany); G. Gold, S. Delp, R. Fahrig, Stanford Univ. (United States)

796124 Functional phase-correlated micro-CT imaging of small rodents with low dose [7961-75] S. Sawall, F. Bergner, A. Hess, Friedrich-Alexander-Univ. of Erlangen-Nürnberg (Germany); R. Lapp, M. Mronz, CT Imaging GmbH (Germany); M. Karolczak, M. Kachelrieß, Friedrich-Alexander-Univ. of Erlangen-Nürnberg (Germany)

796125 Scatter correction for cone-beam computed tomography using moving blocker strips [7961-76]

J. Wang, W. Mao, T. Solberg, The Univ. of Texas Southwestern Medical Ctr. at Dallas (United States)

796126 Single-scan scatter correction for cone-beam CT using a stationary beam blocker: a preliminary study [7961-77]

T. Niu, L. Zhu, Georgia Institute of Technology (United States) 


\section{Part Two}

\section{SESSION 15 DOSE}

796127 Verification of the performance accuracy of a real-time skin-dose tracking system for interventional fluoroscopic procedures [7961-78]

D. R. Bednarek, J. Barbarits, V. K. Rana, S. P. Nagaraja, M. S. Josan, S. Rudin, Univ. at Buffalo (United States)

796128 Energy deposition in the breast during CT scanning: quantification and implications for dose reduction [7961-79]

F. Rupcich, Marquette Univ. (United States); I. Kyprianou, A. Badal, U.S. Food and Drug Administration (United States); T. G. Schmidt, Marquette Univ. (United States)

796129 Uncertainties of organ absorbed doses to patients from 18f-choline [7961-80]

W. B. Li, T. Janzen, M. Zankl, A. Giussani, C. Hoeschen, Helmholtz Zentrum München (Germany)

7961 2A The feasibility of universal DLP-to-risk conversion coefficients for body CT protocols [7961-81] X. Li, E. Samei, W. P. Segars, E. K. Paulson, D. P. Frush, Duke Univ. (United States)

$79612 B \quad X$-ray dose reduction by adaptive source equalization and electronic region-of-interest control [7961-82]

S. Burion, A. Sandman, K. Bechtel, Triple Ring Technologies, Inc. (United States); E. Solomon, NovaRay Medical, Inc. (United States); T. Funk, Triple Ring Technologies, Inc. (United States)

7961 2C Effect of contrast magnitude and resolution metric on noise-resolution tradeoffs in x-ray CT imaging: a comparison of non-quadratic penalized alternating minimization and filtered backprojection algorithms [7961-83]

J. D. Evans, Virginia Commonwealth Univ. (United States); D. G. Politte, B. R. Whiting,

J. A. O'Sullivan, Washington Univ. in St. Louis (United States); J. F. Williamson, Virginia

Commonwealth Univ. (United States)

\section{SESSION 16 SPECIAL SESSION I: DOSE}

7961 2D Definitions and outlook targeting $x$-ray exposure of patients in diagnostic imaging (Invited Paper) [7961-84]

D. F. Regulla, Helmholtz Zentrum München GmbH (Germany)

$79612 \mathrm{~F} \quad$ How do we measure dose and estimate risk? (Invited Paper) [7961-86]

C. Hoeschen, D. Regulla, H. Schlattl, N. Petoussi-Henss, W. B. Li, M. Zankl, Helmholtz Zentrum München (Germany)

$79612 \mathrm{G}$ The accuracy of estimated organ doses from Monte Carlo CT simulations using cylindrical regions of interest within organs [7961-87]

M. Khatonabadi, J. Sandberg, Univ. of California, Los Angeles (United States); N. Eshghi, Heinrich-Heine-Univ. Düsseldorf (Germany); J. J. DeMarco, Univ. of California, Los Angeles (United States); E. Angel, Toshiba America Medical Systems, Inc. (United States); A. C. Turner, D. Zhang, C. C. Cagnon, M. F. McNitt-Gray, Univ. of California, Los Angeles (United States) 
$79612 \mathrm{H} \quad$ An algorithm for intelligent sorting of CT-related dose parameters [7961-88]

T. S. Cook, Hospital of the Univ. of Pennsylvania (United States); S. L. Zimmerman, The Johns Hopkins Univ. (United States); S. Steingal, W. W. Boonn, W. Kim, Hospital of the Univ. of Pennsylvania (United States)

\section{SESSION 17 SPECIAL SESSION II: DOSE}

7961 2K Dose reduction using prior image constrained compressed sensing (DR-PICCS) [7961-91] J. Tang, P. Thériault Lauzier, G.-H. Chen, Univ. of Wisconsin-Madison (United States)

$79612 \mathrm{~L} \quad$ A clinical comparison study of a novel statistical iterative and filtered backprojection reconstruction [7961-92]

P. B. Noël, A. A. Fingerle, B. Renger, E. J. Rummeny, M. Dobritz, Technische Univ. München (Germany)

POSTER SESSION: CT

$79612 \mathrm{M}$ Iterative $\mathrm{CT}$ reconstruction integrating SART and conjugate gradient [7961-93]

Y. Pan, Argonne National Lab. (United States); R. Whitaker, The Univ. of Utah (United States)

$79612 \mathrm{~N}$ Iterative helical cone-beam CT reconstruction using graphics hardware: a simulation study [7961-94]

Y. Pan, Argonne National Lab. (United States); R. Whitaker, Univ. of Utah (United States)

796120 Iterative volume of interest image reconstruction in helical cone beam x-ray CT using a stored system matrix approach [7961-95]

J. XU, B. M. W. Tsui, The Johns Hopkins Univ. (United States)

$79612 \mathrm{P} \quad$ Accelerate multi-dimensional CT scanner simulation with GPU [7961-96]

Y. Han, J. Gao, Hitachi (China) Research \& Development Corp. (China); O. Miyazaki, Hitachi Medical Corp. (Japan)

$79612 Q$ OpenCL: a viable solution for high-performance medical image reconstruction? [7961-97] C. Siegl, H. G. Hofmann, B. Keck, M. Prümmer, Friedrich-Alexander-Univ. Erlangen-Nürnberg (Germany); J. Hornegger, Friedrich-Alexander-Univ. Erlangen-Nürnberg (Germany) and Erlangen Graduate School in Advanced Optical Technologies (SAOT) (Germany)

$79612 R \quad$ Improved total variation regularized image reconstruction (iTV) applied to clinical CT data [7961-98]

L. Ritschl, M. Kachelrieß, Friedrich-Alexander-Univ. of Erlangen-Nürnberg (Germany)

796125 Ring artifact corrections in flat-panel detector based cone beam CT [7961-99]

E. M. A. Anas, Bangladesh Univ. of Engineering and Technology (Bangladesh); J. Kim, S. Y. Lee, Kyung Hee Univ. (Korea, Republic of); M. K. Hasan, Bangladesh Univ. of Engineering and Technology (Bangladesh) and Kyung Hee Univ. (Korea, Republic of) 
$79612 T$ Backprojection-filtration image reconstruction from partial cone-beam data for scatter correction [7961-100]

R. Pua, KAIST (Korea, Republic of); J. Min, KAIST (Korea, Republic of) and Nano Focus Ray Inc. (Korea, Republic of); B. Yoo, KAIST (Korea, Republic of); K.-W. Kim, Nano Focus Ray Inc. (Korea, Republic of); G. Cho, S. Cho, KAIST (Korea, Republic of)

$79612 \mathrm{U}$ Fast 4D cone-beam reconstruction using the McKinnon-Bates algorithm with truncation correction and nonlinear filtering [7961-101]

Z. Zheng, Varian Medical Systems (United States) and Stony Brook Univ. (United States);

M. Sun, J. Pavkovich, J. Star-Lack, Varian Medical Systems (United States)

$79612 \mathrm{~W}$ Contrast adaptive total p-norm variation minimization approach to $\mathrm{CT}$ reconstruction for artifact reduction in reduced-view brain perfusion CT [7961-103]

C. W. Kim, Seoul National Univ. (Korea, Republic of) and Seoul National Univ. College of Medicine (Korea, Republic of); J. H. Kim, Seoul National Univ. (Korea, Republic of)

$79612 X \quad$ Expectation maximization and total variation-based model for computed tomography reconstruction from undersampled data [7961-104]

M. Yan, L. A. Vese, Univ. of California, Los Angeles (United States)

$79612 Y \quad$ A comparison of four algorithms for metal artifact reduction in CT imaging [7961-105]

C. Golden, National Univ. of Ireland Galway (Ireland) and Stanford Univ. (United States);

S. R. Mazin, F. E. Boas, G. Tye, P. Ghanouni, G. Gold, M. Sofilos, N. J. Pelc, Stanford Univ.

(United States)

$796122 \quad$ A study on regularization parameter choice for interior tomography based on truncated Hilbert transform [7961-107]

J. Wu, X. Mou, S. Tang, Xi'an Jiaotong Univ. (China)

796130 Interior tomography from low-count local projections and associated Hilbert transform data [7961-108]

Q. XU, Xi'an Jiaotong Univ. (China); H. Yu, Wake Forest Univ. Health Sciences (United States); X. Mou, Xi'an Jiaotong Univ. (China); G. Wang, Wake Forest Univ. Health Sciences (United

States) and Virginia Polytechnic Institute and State Univ. (United States)

796131 Compressed sensing algorithms for fan-beam CT image reconstruction [7961-109] J. Zhang, J. Wang, G. Xu, Univ. of Wisconsin-Milwaukee (United States); J.-B. Thibault, GE Healthcare (United States)

796132 Low-dose dual-energy cone-beam CT using a total-variation minimization algorithm [7961-110]

J. Min, KAIST (Korea, Republic of) and Nano Focus Ray Inc. (Korea, Republic of); T. Lee, KAIST (Korea, Republic of); K. Kim, Nano Focus Ray Inc. (Korea, Republic of); G. Cho, S. Cho, KAIST (Korea, Republic of)

796133 Refinement of motion correction strategies for lower-cost CT for under-resourced regions of the world [7961-111]

J. R. Wells, W. P. Segars, C. J. N. Kigongo, Duke Univ. Medical Ctr. (United States);

J. T. Dobbins III, Duke Univ. Medical Ctr. (United States) and Duke Univ. (United States) 
796134 Accelerating statistical image reconstruction algorithms for fan-beam x-ray CT using cloud computing [7961-112]

S. Srivastava, A. R. Rao, V. Sheinin, IBM Thomas J. Watson Research Ctr. (United States)

796135 Quantitative evaluation method of noise texture for iteratively reconstructed x-ray CT images [7961-113]

P. Thériault Lauzier, J. Tang, G.-H. Chen, Univ. of Wisconsin-Madison (United States)

796136 An efficient scatter correction algorithm based on pre-reconstructed images of contrast enhancement and sparse-viewed Monte Carlo simulation [7961-114]

H. Yan, X. Mou, Xi'an Jiaotong Univ. (China)

796137 Task-based comparative study of iterative image reconstruction methods for limited-angle x-ray tomography [7961-115]

R. Zeng, K. J. Myers, U.S. Food and Drug Administration (United States)

796138 Limited data tomographic image reconstruction via dual formulation of total variation minimization [7961-116]

K. E. Jang, Y. Sung, K. Lee, J. Lee, Samsung Advanced Institute of Technology (Korea, Republic of); S. Cho, KAIST (Korea, Republic of)

796139 Cone-beam CT data-driven pose correction for analytic reconstruction methods [7961-1 17] J. Cates, The Univ. of Utah (United States); Y. Pan, Argonne National Lab. (United States);

V. Battle, GE Healthcare (United States); R. Whitaker, The Univ. of Utah (United States)

$79613 \mathrm{~A}$ A simple image based method for obtaining electron density and atomic number in dual energy CT [7961-118]

T. P. Szczykutowicz, Z. Qi, G.-H. Chen, Univ. of Wisconsin-Madison (United States)

$79613 \mathrm{~B}$ A scatter artifact reduction technique in dual-energy computed tomography systems [7961-119]

J. Fan, N. Chandra, J. Hsieh, GE Healthcare (United States)

$79613 \mathrm{C}$ Investigation of a method to estimate the MTF and NPS of CT towards creating an international standard [7961-120]

C. C. Brunner, Technische Univ. München (Germany) and Helmholtz Zentrum München (Germany); B. Renger, Technische Univ. München (Germany); C. Hoeschen, Helmholtz Zentrum München (Germany); I. S. Kyprianou, U.S. Food and Drug Administration (United States)

7961 3D XCAT/DRASIM: a realistic CT/human-model simulation package [7961-121]

G. S. K. Fung, The Johns Hopkins Univ. (United States); K. Stierstorfer, Siemens Healthcare (Germany); W. P. Segars, Duke Univ. (United States); K. Taguchi, The Johns Hopkins Univ. (United States); T. G. Flohr, Siemens Healthcare (Germany); B. M. W. Tsui, The Johns Hopkins Univ. (United States) 
7961 3E Longitudinal tube modulation for chest and abdominal CT examinations: impact on effective patient doses calculations [7961-122]

F. Zanca, K. Michielsen, M. Depuydt, J. Jacobs, J. Nens, K. Lemmens, R. Oyen, H. Bosmans, Univ. Hospitals Leuven (Belgium)

7961 3F Dosimetric quality control of Eclipse treatment planning system using pelvic digital test object [7961-123]

Y. Benhdech, IRCCYN, CNRS, Univ. of Nantes (France) and QualiFormeD SARL (France):

S. Beaumont, QualiFormeD SARL (France); J. Guédon, IRCCyN, CNRS, Univ. of Nantes

(France); S. Crespin, Ctr. Hospitalier Départemental (France)

$79613 G$ Estimation of organ and effective dose to the patient during spinal surgery with a cone-beam O-arm system [7961-124]

M. Söderberg, K. Abul-Kasim, A. Ohlin, M. Gunnarsson, Skåne Univ. Hospital Malmö (Sweden)

$79613 \mathrm{H} \quad$ Monte Carlo modeling of the scatter radiation doses in IR [7961-125]

E. Mah, Medical Univ. of South Carolina (United States); W. He, Clemson Univ. (United States); W. Huda, Medical Univ. of South Carolina (United States); H. Yao, Clemson Univ. (United States); B. Selby, Medical Univ. of South Carolina (United States)

7961 3J Fluence estimation by deconvolution via l1-norm minimization [7961-127]

J. C. García Hernández, D. Lazaro-Ponthus, M. Gmar, J. Barthe, CEA, LIST (France)

7961 3K A novel noise suppression solution in cone-beam CT images [7961-128]

Y. Fan, Stony Brook Univ. (United States); H. Lu, Fourth Military Medical Univ. (China); H. Zhu, Stony Brook Univ. (United States); J. Wang, The Univ. of Texas Southwestern Medical Ctr. at Dallas (United States); Q. Lin, Z. Liang, Stony Brook Univ. (United States)

7961 3L Noise reduction by projection direction dependent diffusion for low dose fan-beam x-ray computed tomography [7961-129]

S. Tang, Xi'an Jiaotong Univ. (China) and Xi'an Univ. of Posts and Telecommunications (China); X. Mou, Xi'an, Y. Zhang, Xi'an Jiaotong Univ. (China); H. Yu, Wake Forest Univ. Health Sciences (United States)

$79613 \mathrm{M}$ Radiation dose reduction in computed tomography (CT) using a new implementation of wavelet denoising in low tube current acquisitions [7961-130]

Y. Tao, S. Brunner, J. Tang, M. Speidel, H. Rowley, M. VanLysel, G.-H. Chen, Univ. of Wisconsin-Madison (United States)

$79613 \mathrm{~N} \quad$ Noise characteristics of $\mathrm{x}$-ray differential phase contrast $\mathrm{CT}$ [7961-131]

J. Zambelli, K. Li, N. Bevins, Z. Qi, G.-H. Chen, Univ. of Wisconsin-Madison (United States)

796130 Contrast-to-noise of a non-ideal multi-bin photon-counting x-ray detector [7961-132] J. E. Tkaczyk, V. Lobastov, D. D. Harrison, GE Global Research (United States); A. S. Wang, Stanford Univ. (United States)

$79613 \mathrm{P} \quad$ MCNP simulation of radiation doses distributions in a water phantoms simulating interventional radiology patients [7961-134]

W. He, Clemson Univ. (United States); E. Mah, W. Huda, B. Selby, Medical Univ. of South Carolina (United States); H. Yao, Clemson Univ. (United States) 
$79613 Q \quad$ Noise reduction in dual-source CT scanning [7961-135]

M. Petersilka, B. Krauss, K. Stierstorfer, Siemens AG (Germany)

$79613 R \quad$ Relative dose in dual energy fast-kVp switching and conventional $k V p$ imaging: spatial frequency dependent noise characteristics and low contrast imaging [7961-136]

G. K. Yadava, N. Chandra, J. Hsieh, GE Healthcare (United States)

796135 Determination of 3D flow velocity distributions from single-plane angiographic sequences [7961-137]

K. R. Hoffmann, Univ. at Buffalo (United States) and Imagination Software Corp. (United States); T. Dorazio, J. Lee, J.-H. Jung, E. B. Pitman, Univ. at Buffalo (United States); A. Walczak, Univ. at Buffalo (United States) and Imagination Software Corp. (United States); X. Chen, Univ. at Buffalo (United States)

7961 3T Susceptibility quantification in MRI using modified conjugate gradient least square method [7961-138]

L. Wang, J. Langley, Q. Zhao, The Univ. of Georgia (United States)

$79613 \mathrm{U}$ Direct reconstruction of $\mathrm{T}_{1}$ from $\mathrm{k}$-space using a radial saturation-recovery sequence [7961-139]

L. Chen, E. V. R. DiBella, The Univ. of Utah (United States)

$79613 \mathrm{~V}$ Histogram analysis of ADC in brain tumor patients [7961-140]

D. Banerjee, Old Dominion Univ. (United States); J. Wang, The Univ. of Texas M.D. Anderson Cancer Ctr. (United States); J. Li, Old Dominion Univ. (United States)

7961 3W The development and application of calculated readout in spectral parallelism in magnetic resonance imaging [7961-141]

L. Vu, S. S. So, S. Obruchkov, A. T. Cenko, J. T. Meade, Univ. of Waterloo (Canada);

K. Bradshaw, Sentinelle Medical Inc. (Canada); C. Lemaire, H. Peemoeller, S. Rasheed,

A. R. Hajian, Univ. of Waterloo (Canada); J. K. Kim, Thunder Bay Regional Research Institute (Canada); C. Piron, Sentinelle Medical Inc. (Canada)

$79613 X$ Voxel magnetic field disturbance from remote vasculature in BOLD fMRI [7961-142]

Z. Chen, Z. Chen, The Mind Research Network (United States); V. Calhoun, The Mind Research Network (United States) and Univ. of New Mexico (United States)

$79613 Y$ Multiresolution voxel decomposition of complex-valued BOLD signals reveals phasor turbulence [7961-143]

Z. Chen, Z. Chen, The Mind Research Network (United States); V. Calhoun, The Mind Research Network (United States) and Univ. of New Mexico (United States)

796132 Wavelet encoded MR image reconstruction with compressed sensing [7961-144]

Z. Liu, B. Nutter, J. Ao, S. Mitra, Texas Tech Univ. (United States) 
796140 Modified total variation norm for the maximum a posteriori ordered subsets expectation maximization reconstruction in fan-beam SPECT brain perfusion imaging [7961-145] A. Krol, SUNY Upstate Medical Univ. (United States); Z. Yang, Sun Yat-sen Univ. (China) and SUNY Upstate Medical Univ. (United States); Y. Xu, Sun Yat-sen Univ. (China) and Syracuse Univ. (United States); A. Wismüller, Univ. of Rochester Medical Ctr. (United States);

D. H. Feiglin, SUNY Upstate Medical Univ. (United States)

$796141 \quad$ New method for tuning hyperparameter for the total variation norm in the maximum a posteriori ordered subsets expectation maximization reconstruction in SPECT myocardial perfusion imaging [7961-146]

Z. Yang, Sun Yat-sen Univ. (China) and SUNY Upstate Medical Univ. (United States); A. Krol, SUNY Upstate Medical Univ. (United States); Y. XU, SUn Yat-sen Univ. (China) and Syracuse Univ. (United States); D. H. Feiglin, SUNY Upstate Medical Univ. (United States)

796142 Effect of de-noising and DDRV correction on cone-beam SPECT reconstruction with non-uniform attenuation [7961-147]

H. Zhang, J. Wen, Beijing Institute of Technology (China); W. Yin, Beijing Univ. of Technology (China); C. Li, K. Zhang, Beijing Institute of Technology (China); Z. Liang, Stony Brook Univ. (United States)

796143 Quality controls and delineation protocol of PET/CT gated acquisition in function of the movement amplitude, size of spheres, and signal over background ratio [7961-148] C. Jaudet, D. Didierlaurent, J. Nalis, L. O. Dierickx, O. Caselles, F. Courbon, Institut Claudius Regaud (France)

796144 Using spherical basis functions on a polar grid for iterative image reconstruction in small animal PET [7961-149]

J. Cabello, J. F. Oliver, M. Rafecas, Univ. de València (Spain)

796145 Full modeling of AX-PET: a new PET device with axially oriented crystals based on Geant4 and GATE [7961-150]

P. Solevi, J. F. Oliver, J. Gillam, M. Rafecas, Univ. de València (Spain)

796146 Observing the high resolution capabilities of a silicon PET insert probe [7961-151]

K. Brzeziński, J. F. Oliver, J. Gillam, C. Lacasta, M. Rafecas, Univ. de València (Spain)

796147 Ultrafast image reconstruction of a dual-head PET system by use of CUDA architecture [7961-152]

Y. Hung, National Taiwan Univ. (Taiwan); Y. Dong, Illinois Institute of Technology (United States) and Toshiba Medical Research Institute USA, Inc. (United States); F. R. Chern, W. Wang, National Taiwan Univ. (Taiwan); C.-M. Kao, C.-T. Chen, The Univ. of Chicago (United States); C.-Y. Chou, National Taiwan Univ. (Taiwan)

796148 Evaluation of image gating as an approach for noise estimation and optimisation of SPECT images [7961-153]

K. Alzimami, King Saud Univ. (Saudi Arabia) and Univ. of Surrey (United Kingdom); S. Sassi, Royal Marsden Hospital NHS Foundation Trust (United Kingdom); A. Alshehri, Riyadh Military Hospital (Saudi Arabia); N. Spyrou, Univ. of Surrey (United Kingdom) and King Saud Univ. (Saudi Arabia); A. Britten, St. George's Hospital (United Kingdom) 
796149 Singles-prompt: a novel method to estimate random coincidences by using prompts and singles information [7961-154]

J. F. Oliver, M. Rafecas, Univ. de València (Spain)

\section{Part Three}

7961 4A An investigation of an application specific PET prototype with inhomogeneous-energy resolution detectors [7961-155]

J. Liu, Q. Xie, L. Wan, Wuhan National Lab. for Optoelectronics (China) and Huazhong Univ. of Science and Technology (China)

$79614 \mathrm{~B} \quad$ Basic design and simulation of a SPECT microscope for in vivo stem cell imaging [7961-156] R. A. Moats, Y. Tang, Children's Hospital of Los Angeles (United States); J. W. Hugg, Gamma Medica (United States); D. Meier, Gamma Medica (Norway); D. Koos, California Institute of Technology (United States); N. E. Hartsough, DxRay (United States); B. E. Patt,

D. J. Wagenaar, Gamma Medica (United States)

\section{SESSION 23 POSTER SESSION: X-RAY IMAGING}

7961 4C K-edge subtraction imaging using a pixellated energy-resolving detector [7961-09] S. Pani, S. C. Saifuddin, Univ. of Surrey (United Kingdom); C. Christodoulou, Univ. College London (United Kingdom); M. Veale, P. Seller, Rutherford Appleton Lab. (United Kingdom); R. D. Speller, Univ. College London (United Kingdom); M. Wilson, Rutherford Appleton Lab. (United Kingdom); J. W. Scuffham, Univ. of Surrey (United Kingdom) and Royal Surrey County Hospital NHS Foundation Trust (United Kingdom)

$79614 \mathrm{D} \quad$ Verification of nonlinearity in digital $x$-ray images using surrogate method [7961-157] A. Sugiura, Gifu Univ. of Medical Science (Japan) and Nagoya City Univ. (Japan); K. Yokoyama, Nagoya City Univ. (Japan); H. Takada, Univ. of Fukui (Japan); N. Yasuda, A. Horii, Gifu Univ. of Medical Science (Japan); K. Kida, Kasugai Municipal Hospital (Japan)

$79614 \mathrm{E} \quad$ A software tool for quality assurance of computed/digital radiography (CR/DR) systems [7961-158]

N. Desai, iCRco, Inc. (United States); D. J. Valentino, iCRco, Inc. (United States) and Univ. of California, Los Angeles (United States)

$79614 \mathrm{~F} \quad$ Validation of a method to convert an image to appear as if acquired using a different digital detector [7961-159]

A. Mackenzie, The Royal Surrey County Hospital NHS Foundation Trust (United Kingdom); A. Workman, Forster Green Hospital (United Kingdom); D. R. Dance, The Royal Surrey County Hospital NHS Foundation Trust (United Kingdom) and Univ. of Surrey (United Kingdom); M. Yip, K. Wells, Univ. of Surrey (United Kingdom); K. C. Young, The Royal Surrey County Hospital NHS Foundation Trust (United Kingdom) and Univ. of Surrey (United Kingdom)

7961 4G Measuring the presampled MTF from a reduced number of flat-field images using the noise response (NR) method [7961-160]

A. Kuhls-Gilcrist, Toshiba America Medical Systems, Inc. (United States); A. Jain,

D. R. Bednarek, S. Rudin, Toshiba Stroke Research Ctr., Univ. at Buffalo (United States) 
$79614 \mathrm{H} \quad$ CZT detector in multienergy $\mathbf{x}$-ray imaging with different pixel sizes and pitches: Monte Carlo simulation studies [7961-161]

Y.-N. Choi, H.-J. Kim, H.-M. Cho, C.-L. Lee, H.-S. Park, D.-H. Kim, S.-W. Lee, H.-J. Ryu, Yonsei Univ. (Korea, Republic of)

$796141 \quad$ Effect of $x$-ray incident direction and scintillator layer design on image quality of indirect-conversion flat-panel detector with GOS phosphor [7961-162]

K. Sato, F. Nariyuki, H. Nomura, A. Takasu, S. Fukui, M. Nakatsu, Y. Okada, T. Nabeta, Y. Hosoi, FUJIFILM Corp. (Japan)

7961 4J Graphical user interface for a dual-module EMCCD x-ray detector array [7961-163] W. Wang, C. lonita, A. Kuhls-Gilcrist, Y. Huang, B. Qu, S. K. Gupta, D. R. Bednarek, S. Rudin, Toshiba Stroke Research Ctr., Univ. at Buffalo (United States)

7961 4K CMOS image sensor based $\mathrm{x}$-ray detector noise characterization and its fixed pattern noise correction method [7961-164]

J. XU, B. Nguyen, Suni Medical Imaging, Inc. (United States)

7961 4L Selenium coated CMOS passive pixel array for medical imaging [7961-165]

S. H. Majid, A. H. Goldan, B. Hadji, Univ. of Waterloo (Canada); G. Belev, Canadian Light Source (Canada); S. Kasap, Univ. of Saskatchewan (Canada); K. S. Karim, Univ. of Waterloo (Canada)

7961 4M CMOS digital intra-oral sensor for $x$-ray radiography [7961-166]

X. Liu, Fairchild Imaging Inc. (United States); A. Byczko, M. Choi, L. Chung, H. Do, B. Fowler, R. Ispasoiu, K. Joshi, T. Miller, A. Nagy, D. Reaves, B. Rodricks, D. Teeter, G. Wang, F. Xiao, Fairchild Imaging Inc (United States)

$79614 \mathrm{~N}$ Design and fabrication of single grain TFTs and lateral photodiodes for low dose x-ray detection [7961-167]

A. Arslan, R. Ishihara, J. Derakhshandeh, C. I. M. Beenakker, Delft Univ. of Technology (Netherlands)

796140 Photon quantum shot noise limited array in amorphous silicon technology for protein crystallography applications [7961-169]

M. Y. Yazdandoost, K. Wang, K. S. Karim, Univ. of Waterloo (Canada)

$79614 \mathrm{P}$ Study of gain phenomenon in lateral metal-semiconductor-metal detectors for indirect conversion medical imaging [7961-170]

S. Abbaszadeh, N. Allec, K. Wang, F. Chen, K. S. Karim, Univ. of Waterloo (Canada)

$79614 \mathrm{Q}$ Complete erasing of ghost images caused by deeply trapped electrons on computed radiography plates [7961-171]

H. Ohuchi, Tohoku Univ. (Japan); Y. Kondo, Ishinomaki Senshu Univ. (Japan) 
79614 Evaluation and comparison of high-resolution (HR) and high-light (HL) phosphors in the micro-angiographic fluoroscope (MAF) using generalized linear systems analyses (GMTF, GDQE) that include the effect of scatter, magnification, and detector characteristics [7961-173]

S. K. Gupta, A. Jain, D. R. Bednarek, S. Rudin, Toshiba Stroke Research Ctr., Univ. at Buffalo (United States)

\section{SESSION 25 POSTER SESSION: NOVEL SYSTEMS, OTHER}

7961 4T LBP based detection of intestinal motility in WCE images [7961-174]

G. Gallo, E. Granata, Univ. degli Studi di Catania (Italy)

$79614 \mathrm{U}$ Temperature anomaly detection and estimation using microwave radiometry and anatomical information [7961-175]

P. Kelly, T. Sobers, B. St. Peter, P. Siqueira, Univ. of Massachusetts Amherst (United States);

G. Capraro, Alpert Medical School, Brown Univ. (United States)

$79614 \mathrm{~V}$ Optimization of differential phase-contrast imaging setups using simulative approaches [7961-176]

A. Ritter, P. Bartl, F. Bayer, J. Durst, W. Haas, T. Michel, G. Pelzer, T. Weber, G. Anton,

Friedrich-Alexander-Univ. of Erlangen-Nürnberg (Germany)

7961 4W SEM and microCT validation for en face OCT imagistic evaluation of endodontically treated human teeth [7961-178]

M. L. Negruțiu, L. Nica, C. Sinescu, F. Topală, Univ. of Medicine and Pharmacy Victor Babes (Romania); C. Ioniță, Univ. at Buffalo (United States); A. Bradu, Univ. of Kent (United Kingdom); E. L. Petrescu, D. M. Pop, M. Romînu, Univ. of Medicine and Pharmacy Victor Babes (Romania); A. Gh. Podoleanu, Univ. of Kent (United Kingdom)

$79614 X$ Performance evaluation of a differential phase-contrast cone-beam (DPC-CBCT) system for soft tissue imaging [7961-179]

Y. Yu, R. Ning, W. Cai, Univ. of Rochester (United States)

$79614 \mathrm{Y} \quad \mathrm{X}$-ray fube-based phase CT: spectrum polychromatics and imaging performance [7961-180]

X. Tang, Y. Yang, S. Tang, Emory Univ. School of Medicine (United States)

$79614 Z \quad X$-ray phase computed tomography for nanoparticulated imaging probes and therapeutics: preliminary feasibility study [7961-181]

$X$. Tang, Y. Yang, S. Tang, Emory Univ. School of Medicine (United States)

796150 A new technology for terahertz imaging in breast cancer margin determination [7961-182]

S. Yngvesson, B. St. Peter, P. Siqueira, P. Kelly, Univ. of Massachusetts Amherst (United States);

S. Glick, A. Karellas, Univ. of Massachusetts Medical School (United States)

796151 Retaining axial-lateral orthogonality in steered ultrasound data to improve image quality in reconstructed lateral displacement data [7961-183]

L. Garcia, J. Fromageau, The Institute of Cancer Research and Royal Marsden NHS Trust (United Kingdom); R. J. Housden, G. M. Treece, Univ. of Cambridge (United Kingdom); C. Uff, J. C. Bamber, The Institute of Cancer Research and Royal Marsden NHS Trust (United Kingdom) 
796152 Simulation of ultrasound backscatter images from fish [7961-184]

A. H. Pham, B. Stage, Technical Univ. of Denmark (Denmark); M. C. Hemmsen, Technical Univ. of Denmark (Denmark) and BK Medical (Denmark); B. Lundgren, Technical Univ. of Denmark (Denmark); M. M. Pedersen, Technical Univ. of Denmark (Denmark) and Rigshospitalet (Denmark); T. B. Pedersen, Rigshospitalet (Denmark); J. A. Jensen, Technical Univ. of Denmark (Denmark)

796153 New method to test the gantry, collimator, and table rotation angles of a linear accelerator used in radiation therapy [7961-185]

S. Beaumont, T. Torfeh, R. Latreille, QualiFormeD (France); Y. Ben Hdech, QualiFormeD (France) and IRCCYN, CNRS, Univ. de Nantes (France); J. Guedon, IRCCYN, CNRS, Univ. de Nantes (France)

796154 Factors for conversion between human and automatic read-outs of CDMAM images [7961-186]

J. Hummel, Medical Univ. of Vienna (Austria) and Wilhelminenspital (Austria); M. Kaar, R. Hoffmann, F. Semturs, N. Brasik, P. Homolka, M. Figl, Medical Univ. of Vienna (Austria)

796155 Image noise sensitivity of dual-energy digital mammography for calcification imaging [7961-187]

X. Chen, Xi'an Jiaotong Univ. (China); R. M. Nishikawa, The Univ. of Chicago (United States); S. Chan, L. Zhang, The Hong Kong Polytechnic Univ. (Hong Kong, China); X. Mou, Xi'an Jiaotong Univ. (China)

796156 Abnormal breast tissue imaging based on multi-energy x-ray [7961-188] D.-G. Kang, S.-M. Han, Y. Sung, S. Lee, Samsung Electronics Co., Ltd. (Korea, Republic of)

796157 High contrast soft tissue imaging based on multi-energy x-ray [7961-189] H.-H. Oh, Y.-H. Sung, S.-S. Kim, J.-H. Kwon, S. Lee, C.-Y. Kim, Samsung Electronics Co., Ltd (Korea, Republic of)

796158 Detailed characterization of 2D and 3D scatter-to-primary ratios of various breast geometries using a dedicated CT mammotomography system [7961-190] J. Shah, J. H. Pachon, P. Madhav, M. P. Tornai, Duke Univ. (United States) and Duke Univ. Medical Ctr. (United States)

796159 Characterization of image quality for 3D scatter-corrected breast CT images [7961-191] J. H. Pachon, J. Shah, M. P. Tornai, Duke Univ. (United States) and Duke Univ. Medical Ctr. (United States)

$79615 \mathrm{~A}$ Evaluation of image quality in computed radiography based mammography systems [7961-192]

A. Singh, V. Bhwaria, iCR Co, Inc. (United States); D. J. Valentino, iCR Co, Inc. (United States) and Univ. of California, Los Angeles (United States)

7961 5C Application of parameters for evaluating different technologies for digitizing film mammograms [7961-194]

R. de Freitas Góes, H. Schiabel, M. A. Zucareli Sousa, Univ. of São Paulo (Brazil) 
$79615 \mathrm{D}$ Evaluation of the quality of image for various breast composition and exposure conditions in digital mammography [7961-195]

M. Yamada, Nagoya Univ. (Japan); Y. Kato, Aichi Medical Univ. (Japan); N. Fujita, Nagoya Univ. Hospital (Japan); Y. Kodera, Nagoya Univ. (Japan)

$79615 \mathrm{E}$ Design and validation of a mathematical breast phantom for contrast-enhanced digital mammography [7961-196]

M. L. Hill, Sunnybrook Research Institute (Canada) and Univ. of Toronto (Canada);

J. G. Mainprize, R. A. Jong, Sunnybrook Health Sciences Ctr. (Canada); M. J. Yaffe,

Sunnybrook Health Sciences Ctr. (Canada) and Univ. of Toronto (Canada)

7961 5F Automatic patient motion detection in digital breast tomosynthesis [7961-197]

B. Ren, Y. Zhang, C. Ruth, A. Smith, L. Niklason, Hologic, Inc. (United States); Z. Tao,

Hologic/R2 (United States); Z. Jing, Hologic/DRC (United States)

$79615 G \quad$ A human observer study for evaluation and optimization of reconstruction methods in breast tomosynthesis using clinical cases [7961-198]

D. Förnvik, Skåne Univ. Hospital (Sweden); A. Jerebko, Siemens Healthcare AG (Germany);

P. Timberg, Skåne Univ. Hospital (Sweden); I. Schasiepen, C. Hofmann, Siemens Healthcare AG (Germany); S. Zackrisson, I. Andersson, Skåne Univ. Hospital (Sweden); T. Mertelmeier, Siemens Healthcare AG (Germany); A. Tingberg, Skåne Univ. Hospital (Sweden)

$79615 \mathrm{H} \quad$ Segmentation of adipose and glandular tissue for breast tomosynthesis imaging using a 3D hidden-Markov model trained on breast MRIs [7961-199]

C. M. Shafer, Duke Univ. (United States); V. L. Seewaldt, Duke Univ. Medical Ctr. (United States); J. Y. Lo, Duke Univ. (United States)

$796151 \quad$ Stationary digital breast tomosynthesis with distributed field emission x-ray tube [7961-200] F. Sprenger, XinRay Systems LLC (United States); X. Calderon, E. Gidcumb, J. Lu, X. Qian, Univ. of North Carolina at Chapel Hill (United States); D. Spronk, XinRay Systems LLC (United States); A. Tucker, G. Yang, O. Zhou, Univ. of North Carolina at Chapel Hill (United States)

$79615 \mathrm{~J}$ The use of detectability indices as a means of automatic exposure control for a digital mammography system (Cum Laude Poster Award) [7961-201]

E. Salvagnini, UZ Gasthuisberg, Univ. of Leuven (Belgium) and SCK •CEN (Belgium);

H. Bosmans, UZ Gasthuisberg, Univ. of Leuven (Belgium); P. Monnin, CHUV, Univ. of Lausanne (Switzerland); L. Struelens, SCK・CEN (Belgium); F. Verdun, CHUV, Univ. of Lausanne (Switzerland); N. W. Marshall, UZ Gasthuisberg, Univ. of Leuven (Belgium)

$79615 \mathrm{~K} \quad$ Investigating the potential for super-resolution in digital breast tomosynthesis (Best Student Paper Award) [7961-202]

R. J. Acciavatti, A. D. A. Maidment, The Univ. of Pennsylvania (United States)

\section{SESSION 27 POSTER SESSION: APPLICATIONS}

$79615 \mathrm{M}$ An approach of long-view tomosynthesis in peripheral arterial angiographic examinations [7961-204]

D. Notohara, K. Nishino, K. Shibata, Shimadzu Corp. (Japan) 
$79615 \mathrm{~N} \quad$ Accurate joint space quantification in knee osteoarthritis: a digital x-ray tomosynthesis phantom study [7961-205]

T. S. Sewell, Milwaukee School of Engineering (United States); K. L. Piacsek, B. A. Heckel, J. M. Sabol, GE Healthcare (United States)

796150 Image performance evaluation of a 3D surgical imaging platform [7961-206] I. E. Petrov, H. N. Nikolov, Robarts Research Institute (Canada); D. W. Holdsworth, M. Drangova, Robarts Research Institute (Canada) and The Univ. of Western Ontario (Canada)

$79615 \mathrm{P} \quad$ Feasibility study of low-dose intra-operative cone-beam CT for image-guided surgery [7961-207]

X. Han, The Univ. of Chicago (United States); S. Shi, Medtronic, Inc. (United States); J. Bian, The Univ. of Chicago (United States); P. Helm, Medtronic, Inc. (United States); E. Y. Sidky, $X$. Pan, The Univ. of Chicago (United States)

$79615 \mathrm{Q}$ Examination of the dental cone-beam CT equipped with flat-panel-detector (FPD) [7961-208]

R. Ito, Nagoya Univ. (Japan); N. Fujita, Nagoya Univ. Hospital (Japan); Y. Kodera, Nagoya Univ. (Japan)

$79615 R \quad$ Four-dimensional volume-of-interest reconstruction for cone-beam computerized tomography based image-guided radiation therapy of the lung [7961-209] M. Ahmad, T. Pan, The Univ. of Texas M.D. Anderson Cancer Ctr. (United States)

$79615 S$ 4D cone beam CT phase sorting using high frequency optical surface measurement during image guided radiotherapy [7961-210]

G. J. Price, T. E. Marchant, J. M. Parkhurst, P. J. Sharrock, The Christie NHS Foundation Trust (United Kingdom); G. A. Whitfield, The Univ. of Manchester (United Kingdom); C. J. Moore, The Christie NHS Foundation Trust (United Kingdom)

$79615 T$ Optimization of four-dimensional cone-beam computed tomography in image-guided radiation therapy of the lung [7961-211]

M. Ahmad, T. Pan, The Univ. of Texas M.D. Anderson Cancer Ctr. (United States)

$79615 \mathrm{U}$ Comparing image quality and radiation dose between new generation MDCT and CBCT systems [7961-212]

O. Sultan, Technische Univ. München (Germany); M. Fiebich, Univ. of Applied Sciences Giessen-Friedberg (Germany); M. Dobritz, B. Renger, E. J. Rummeny, P. B. Noël, Technische Univ. München (Germany)

$79615 \mathrm{~V}$ A comparison of methods for estimating the line spread function of a CT imaging system [7961-213]

S. Abboud, U.S. Food and Drug Administration (United States), Univ. of Maryland, Baltimore (United States), and Univ. of Maryland, College Park (United States); K. Lee, K. Vinehout, Marquette Univ. (United States); S. Paquerault, U.S. Food and Drug Administration (United States); I. S. Kyprianou, U.S. Food and Drug Administration (United States) and Univ. of Maryland, College Park (United States) 
7961 5W Performance evaluation of a sub-millimeter spectrally resolved CT system on pediatric imaging tasks: a simulation [7961-214]

M. Yveborg, M. E. Danielsson, H. Bornefalk, Royal Institute of Technology (Sweden)

$79615 X \quad$ Characteristics of noise and resolution on image reconstruction in cone-beam computed tomography [7961-215]

S.-W. Lee, H.-J. Kim, C.-L. Lee, H.-M. Cho, H.-S. Park, D.-H. Kim, Y.-N. Choi, H.-J. Ryu, Yonsei Univ. (Korea, Republic of)

$79615 Y \quad$ Investigation of the effect of varying scatter-to-primary ratios on nodule contrast in chest tomosynthesis [7961-216]

A. Svalkvist, Univ. of Gothenburg (Sweden); G. Ullman, Linköping Univ. (Sweden) and Uppsala Univ. (Sweden); M. Håkansson, Univ. of Gothenburg (Sweden) and Sahlgrenska Univ. Hospital (Sweden); D. R. Dance, Royal Surrey County Hospital (United Kingdom); M. Sandborg, G. Alm Carlsson, Linköping Univ. (Sweden); M. Båth, Univ. of Gothenburg (Sweden) and Sahlgrenska Univ. Hospital (Sweden)

$79615 Z$ 3D lesion insertion in digital breast tomosynthesis images [7961-217]

M. S. Vaz, Barco, Inc. (United States); Q. Besnehard, C. Marchessoux, Barco NV (Belgium)

796160 A patient image-based technique to assess the image quality of clinical chest radiographs [7961-218]

Y. Lin, E. Samei, Duke Univ. Medical Ctr. (United States); H. Luo, Carestream Health, Inc. (United States); J. T. Dobbins III, H. P. McAdams, Duke Univ. Medical Ctr. (United States); X. Wang, W. J. Sehnert, L. Barski, D. H. Foos, Carestream Health, Inc. (United States)

796161 A new iodinated liver phantom for the quantitative evaluation of advanced CT acquisition and reconstruction techniques [7961-219]

B. Chen, D. Marin, E. Samei, Duke Univ. (United States)

Author Index 


\title{
Conference Committee
}

\author{
Symposium Chairs
}

Maryellen L. Giger, The University of Chicago (United States)

Joseph M. Reinhardt, The University of lowa (United States)

Conference Chairs

Norbert J. Pelc, Stanford University (United States)

Ehsan Samei, Duke University (United States)

Conference Cochair

Robert M. Nishikawa, The University of Chicago (United States)

Program Committee

Guang-Hong Chen, University of Wisconsin-Madison (United States)

Dianna D. Cody, The University of Texas M.D. Anderson Cancer Center (United States)

Mats Danielsson, Royal Institute of Technology (Sweden)

Maria Drangova, Robarts Research Institute (Canada)

Thomas Flohr, Siemens Medical Solutions GmbH (Germany)

Stephen J. Glick, University of Massachusetts Medical School (United States)

Michael Grass, Philips Technologie GmbH (Germany)

Christoph Hoeschen, Helmholtz Zentrum München GmbH (Germany)

Marc Kachelriess, Friedrich-Alexander-Universität Erlangen-Nürnberg (Germany)

Karim S. Karim, University of Waterloo (Canada)

Hee-Joung Kim, Yonsei University (Korea, Republic of)

Despina Kontos, The University of Pennsylvania Health System (United States)

lacovos S. Kyprianou, U.S. Food and Drug Administration (United States)

Jinyi Qi, University of California, Davis (United States)

John A. Rowlands, Thunder Bay Regional Health Sciences Centre (Canada)

John M. Sabol, GE Healthcare (United States)

Taly Gilat Schmidt, Marquette University (United States)

Jeffrey H. Siewerdsen, The Johns Hopkins University (United States)

Katsuyuki Taguchi, The Johns Hopkins Outpatient Center (United States)

Anders Tingberg, Skåne University Hospital, Malmö (Sweden) 
Bruce R. Whiting, Washington University in St. Lovis (United States)

John Yorkston, Carestream Health, Inc. (United States)

\section{Session Chairs}

$1 \quad$ Keynote and Imaging and Health Economics

Norbert J. Pelc, Stanford University (United States)

Ehsan Samei, Duke University (United States)

$2 \quad$ X-ray Imaging

John A. Rowlands, Thunder Bay Regional Health Sciences Centre (Canada)

Christoph Hoeschen, Helmholtz Zentrum München GmbH (Germany)

3 Metrology

Robert M. Nishikawa, The University of Chicago (United States)

John Yorkston, Carestream Health Technology and Innovation Center (United States)

$4 \quad$ Iterative and Statistical Reconstruction

Jinyi Qi, University of California, Davis (United States)

Guang-Hong Chen, University of Wisconsin-Madison (United States)

5 Detectors I

John Yorkston, Carestream Health Technology and Innovation Center (United States)

John A. Rowlands, Thunder Bay Regional Health Sciences Centre (Canada)

6 Detectors II

Karim S. Karim, University of Waterloo (Canada)

Mats Danielsson, Royal Institute of Technology (Sweden)

$7 \quad$ Breast Imaging

Anders Tingberg, Skåne University Hospital, Malmö (Sweden)

Stephen J. Glick, University of Massachusetts Medical School (United States)

8 Tomosynthesis I: Reconstruction

John M. Sabol, GE Healthcare (United States)

Michael Grass, Philips Technologie GmbH (Germany)

9 Tomosynthesis II

Despina Kontos, The University of Pennsylvania Health System (United States)

Anders Tingberg, Skåne University Hospital, Malmö (Sweden) 
10 X-ray Imaging: Phase Contrast, Diffraction

Jeffrey H. Siewerdsen, The Johns Hopkins University (United States)

Taly Gilat Schmidt, Marquette University (United States)

11 Image Reconstruction

Bruce R. Whiting, Washington University in St. Lovis (United States)

Katsuyuki Taguchi, The Johns Hopkins Outpatient Center (United States)

12 CT III: Multi-energy

Thomas G. Flohr, Siemens Medical Solutions GmbH (Germany)

John M. Sabol, GE Healthcare (United States)

13 Novel Systems

Mats Danielsson, Royal Institute of Technology (Sweden)

Taly Gilat Schmidt, Marquette University (United States)

14 CT IV: Cone Beam

Maria Drangova, Robarts Research Institute (Canada)

Marc Kachelriess, Friedrich-Alexander-Universität Erlangen-Nürnberg (Germany)

15 Dose

lacovos S. Kyprianou, U.S. Food and Drug Administration (United States)

Hee-Joung Kim, Yonsei University (Korea, Republic of)

16 Special Session I: Dose

Ehsan Samei, Duke University (United States)

Dianna D. Cody, The University of Texas M.D. Anderson Cancer Center (United States)

17 Special Session II: Dose

Christoph Hoeschen, Helmholtz Zentrum München GmbH (Germany)

Michael F. McNitt-Gray, University of California, Los Angeles (United States)

Special Session III: Panel Discussion

Ehsan Samei, Duke University (United States) 
Downloaded From: https://www.spiedigitallibrary.org/conference-proceedings-of-spie on 26 Apr 2023

Terms of Use: https://www.spiedigitallibrary.org/terms-of-use 